\title{
20
}

\section{Chemistry and Properties of Porous, Organically Modified Silica}

\author{
Helmut Schmidt' and Harald Böttner ${ }^{2}$ \\ IInstitut für Neue Materialien, Universität des Saarlandes Gebäude 43, Im \\ Stadtwald, D-6600 Saarbrücken, Germany \\ 2Fraunhofer-Institut für Physikalische Messtechnik, Heidenhofstrasse 8, D. \\ 7800 Freiburg, Germany
}

\begin{abstract}
Sol-gel techniques were used to prepare porous, organically modified silica materials. The introduction of organic groupings was carried out with alkoxysilanes as precursors; methyl and propyl amino groups were used. The results show that high-porosity materials can be synthesized; the microstructure strongly depends on reaction conditions such as composition, solvent, catalyst type, and concentration. Microstructure tailoring affects mechanical as well as adsorption properties, and custom-made materials such as abrasives and adsorbents with special properties were synthesized.
\end{abstract}

\section{$\mathrm{S}$}

ILICA IS AN OXIDE with innumerable variations. On the basis of this structural variability, a variety of different types of materials have been prepared, such as compact fused silica, in the form of plates, fibers, or finely dispersed pellets, and porous materials. Because compact silica is mostly used for optical components or applications for which high chemical durability is required, porous and finely dispersed materials have completely different applications, for example, as fillers, adsorptive materials, or strengtheners in composites. Various aspects of the chemistry, physics, and applications of silica are described in detail in the book by Iler (1), with special consideration given to finely dispersed and porous materials.

The main preparation method for fused silica still involves melting technology, but a few other methods are used that involve sol-gel or 
related routes (2). For fibers and coatings, sol-gel technology has become more and more important (3-5). For dispersed materials, pyrolytic and precipitation processes are the dominating technologies for large-scale production (6-7). To adapt these types of silica to a variety of special applications, various types of chemical surface modifications have been performed. A survey is given in reference 1. By surface modification (e.g., by organosilicon compounds) the hydrophobicity or hydrophilicity can be varied. For example, chromatographic materials (for reverse-phase chromatographic columns, for example) are prepared by reacting alkylsilanes that have well-defined alkyl chain-lengths (e.g., $C_{8}$ ) with the silica surface (Scheme I):
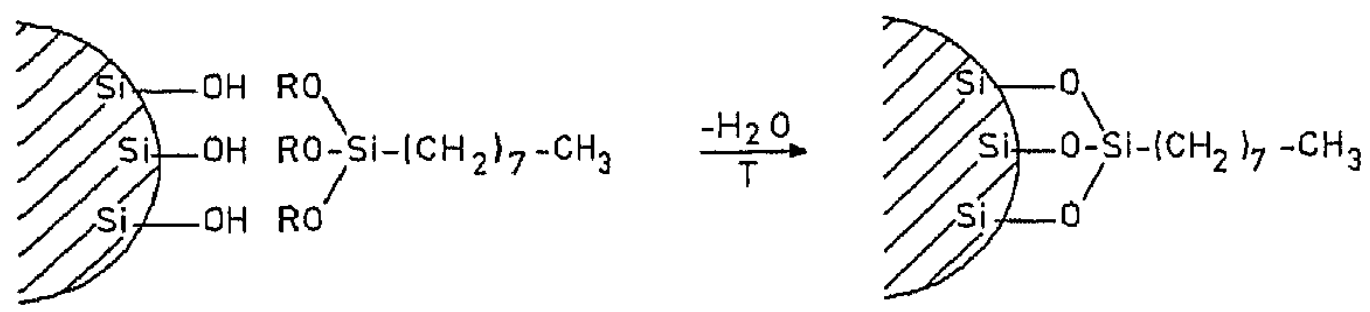

Scheme I.

This type of surface modification, if adequate functional groups are used, can be useful in incorporating silica particles into polymeric matrices (e.g., into rubber for tires) or in increasing the hydrolytic stability of highsurface-area silica (e.g., that used for membranes). Surface modification of silica is a very important principle and is widely commercialized.

\section{General Considerations}

Another principle of modification, the modification of the network by organic groups, is not as important now compared to the surface modification principle. The exchange of an $-\mathrm{O}-$ group of a $\left[\mathrm{SiO}_{4}\right]^{4-}$ tetrahedron by a $\mathrm{CH}_{3}$ group drastically changes the properties of the modified "glass" compared to fused silica. The density drops from about 2.2 (fused silica) to about $1.3 \mathrm{~g} / \mathrm{cm}^{3}$, and the thermal coefficient of expansion increases from $0.5 \times 10^{-6}$ to $100 \times 10^{-6} \mathrm{~K}^{-1}$. Bulk materials modified by $\mathrm{CH}_{3}$ are used as spin-on glasses for coating purposes in microelectronics. They can be oxidized to $\mathrm{SiO}_{2}$ glassy films if desirable (8). The partial substitution of $\equiv \mathrm{Si}-\mathrm{O}-$ bonds by $\equiv \mathrm{Si}-\mathrm{CH}_{3}$ groups leads to densification temperatures far below the densification of inorganic $\mathrm{SiO}_{2}$ sol-gel films. The examples indicate an interesting effect of organic 
modification of silica on properties as well as on structure. This chapter focuses on porous silica materials that have been bulk-modified by $\equiv \mathrm{Si}-\mathrm{C}$ bonds and derived by sol-gel methods.

High porosity or high surface areas can be obtained by various preparation or special processing techniques, for example, by leaching of phase-separated sodium borosilicate glasses. Small dimensions of building units are required; small particles or small pores between units must be created (Figure 1). In materials with small pores between units, a high rigidity of material is required to avoid the collapse of the pores during the network synthesis.

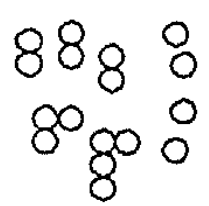

a)

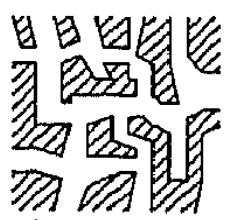

b)

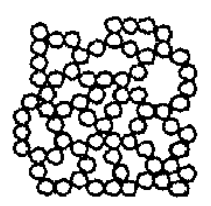

c)

Figure 1. Model of high-surface-area materials: a, small particles; $b$ " "reverse" system, small pores; and $c$, porosity generated by aggregation of small particles (a).

The required network rigidity results from the three-dimensional cross-linking of the $\left[\mathrm{SiO}_{4}\right]^{4-}$ tetrahedrons. Bulk modification by introduction of organic units through $\equiv \mathrm{Si}-\mathrm{C}$ - bonds leads to a change of network connectivity and should also affect porosity or surface area. On the other hand, in this case the modification becomes an intrinsic property that should not be affected by surface corrosion (Scheme II), because after removal of the surface layer by hydrolytic processes, the following layer exhibits the corresponding structure and properties. The properties to be developed determine whether a surface or a bulk modification is more appropriate.

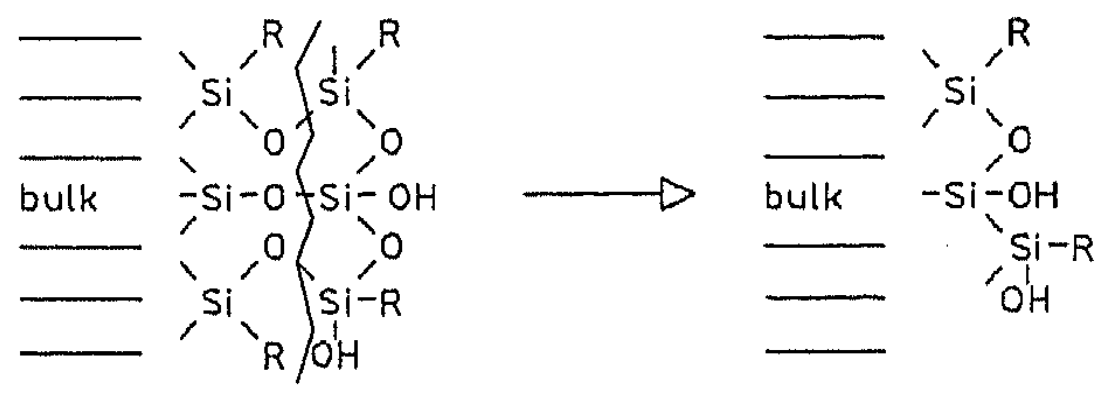

Scheme II. Model of corrosion of organic modification of silica ("bulk" denotes the $-\mathrm{CH}_{3}-$ modified structure). 


\section{Preparation of Porous Materials}

Reactivity of Precursors in Sol-Gel Processes. If multicomponent systems are prepared by hydrolysis and condensation of alkoxide precursors in methanol, the reaction rates of hydrolysis and condensation (including aggregation) of the different components become very important for the distribution of the different components. The simple question of how $\mathrm{CH}_{3}$ groups might be distributed within a porous two-component system with $\mathrm{Si}(\mathrm{OR})_{4}$ and $\mathrm{CH}_{3} \mathrm{Si}(\mathrm{OR})_{3}$ or $\left(\mathrm{CH}_{3}\right)_{2} \mathrm{Si}(\mathrm{OR})_{2}$ as precursors leads to serious mechanistic problems. A comparison of the hydrolysis rates with acid catalysis indicates an increase with increasing number of organic ligands $(9-11)$ and the opposite with bases. The effect on specific surface areas of the resulting materials is shown in Figure 2. Similar results with $\left(\mathrm{CH}_{3}\right)_{2} \mathrm{SiO}$-containing systems for membrane formation were obtained with ethanol.

The surface areas were measured by multipoint BrunauerEmmett-Teller (BET) techniques. In $\mathrm{NH}_{3}$-catalyzed materials, the fraction of micropores is extremely low $(<1 \mathrm{vol} \%)$. In acid catalysis, the micropore content increased with decreasing surface area. The $\mathrm{CH}_{3}$ content was determined by IR spectroscopic analysis of $\mathrm{CH}_{3}$ groups only in $\mathrm{NH}_{3}$ catalyzed composites could a loss of $\mathrm{CH}_{3}$-containing units be observed.

The experimental process for synthesizing the porous materials was standardized as follows. The silanes were mixed in the ratios as indicated in $\mathrm{MeOH}$ (Me, methyl) as solvent, and then at room temperature $1 \mathrm{~mol}$ of water per $\equiv$ SiOR group was added. The water contained the indicated concentration of catalysts. The reaction mixture was stirred for $5 \mathrm{~min}$ and then stored in a closed flask. The two different catalysts show opposite tendencies with respect to increasing concentrations of $\mathrm{CH}_{3}$ groups in the system. With $\mathrm{NH}_{3}$, the surface areas decrease with increasing $\mathrm{CH}_{3}$ group content in both systems $\left(\mathrm{SiO}_{2}-\mathrm{CH}_{3} \mathrm{SiO}_{3 / 2}\right.$ and $\left.\mathrm{SiO}_{2}-\left(\mathrm{CH}_{3}\right)_{2} \mathrm{SiO}\right)$, but there is no significant difference between both systems.

In the acid-catalyzed systems, very high surface areas are observed in $\mathrm{CH}_{3}$-containing composites. The effect of the $\mathrm{HCl}$ concentration is significant. In basic catalysis, the reaction conditions do not seem to influence structure and porosity to the same extent as in the acid case. In acid catalysis, the total surface area increases with decreasing gelling times and increases with increasing $\mathrm{CH}_{3}$ concentrations. The gelling times are given in Table I.

The increase of surface area with increasing $\mathrm{CH}_{3}$ concentration (decreasing network connectivity) can be explained by the interaction of $\mathrm{CH}_{3}$-covered pore walls with water; this interaction leads to reduced interfacial tensions. Synthesis yields are a function of catalyst and composition (Figure 3). This fact can be explained by a reaction rate consideration. As shown in reference 9 , the hydrolysis rate of the $\mathrm{CH}_{3}$ - 

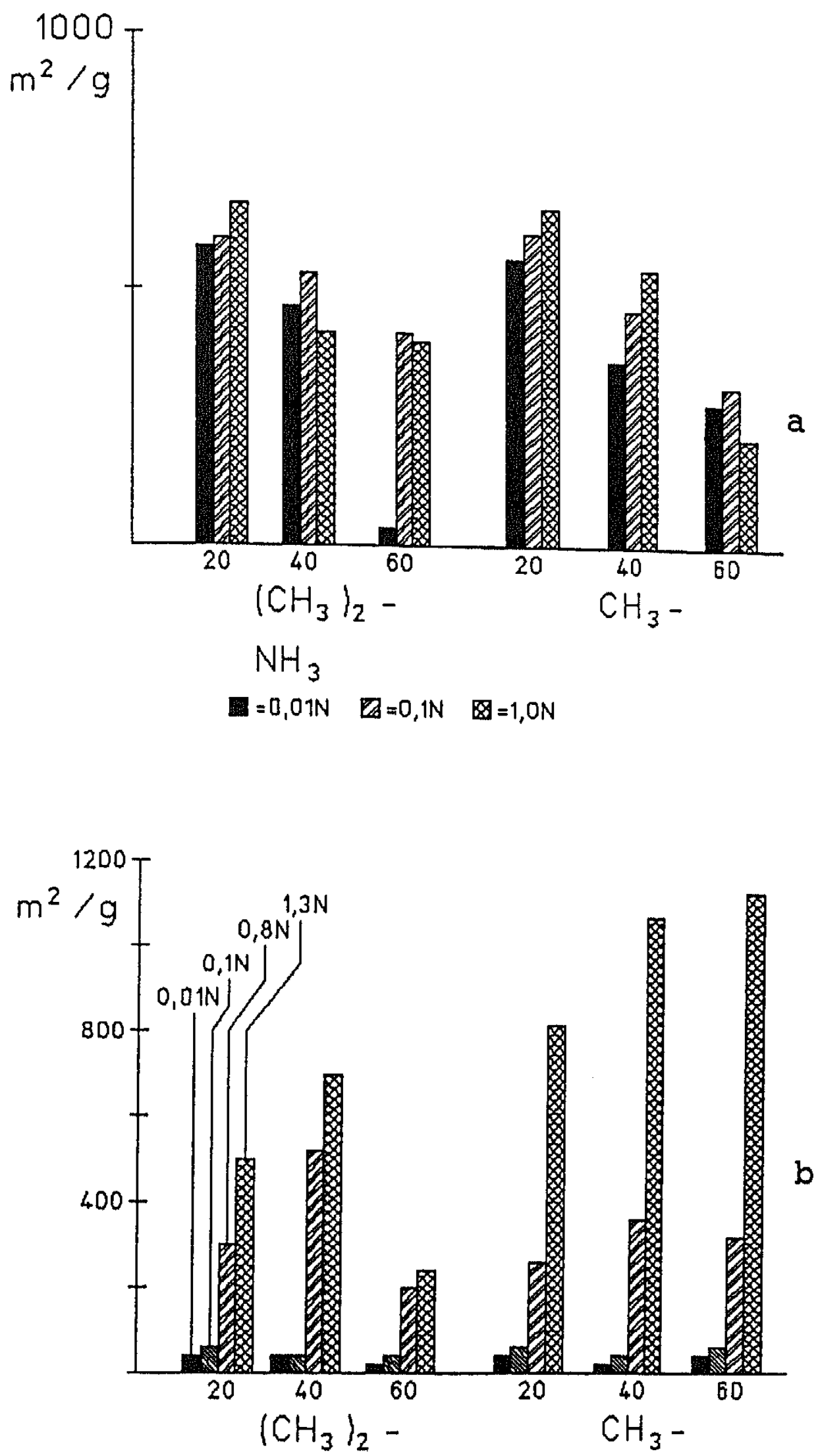

Figure 2. Effect of reaction conditions and composition on the specific surface area of $-\mathrm{CH}_{3}-$ modified silica. [tetramethoxysilane (TMOS) as shown]. Part a: catalyst, $\mathrm{NH}_{3}$; abscissa numbers, weight percent of $\mathrm{CH}_{3} \mathrm{SiO}_{3 / 2}$ or $\left(\mathrm{CH}_{3}\right)_{2} \mathrm{SiO}$.

Part b: catalyst, $\mathrm{HCl}$; abscissa numbers, same as in part $a$. 
Table I. Gelling Times of Various Composites

\begin{tabular}{lcccc}
\hline $\begin{array}{l}\text { Catalyst Type } \\
\text { and Concentration }\end{array}$ & $80: 20$ & $60: 40$ & \multicolumn{1}{c}{$40: 60$} \\
\hline $1 \mathrm{~N} \mathrm{NH}_{3}(2 \mathrm{~N} \mathrm{HCl})$ & $\sim 1\left(\sim 3 \times 10^{5}\right)$ & $\sim 1\left(\sim 3 \times 10^{5}\right)$ & $\sim 1$ & $\left(\sim 3 \times 10^{5}\right)$ \\
$0.1 \mathrm{~N} \mathrm{NH}_{3}(0.1 \mathrm{~N} \mathrm{HCl})$ & $300\left(\sim 23 \times 10^{5}\right)$ & $\sim 840\left(\sim 11 \times 10^{5}\right)$ & $\sim 2700$ & $\left(\sim 13 \times 10^{5}\right)$ \\
$0.01 \mathrm{~N} \mathrm{NH}_{3}(0.01 \mathrm{~N} \mathrm{HCl})$ & $1200\left(\sim 47 \times 10^{5}\right)$ & $\sim 10^{5}\left(\sim 80 \times 10^{5}\right)$ & $\sim 3 \times 10^{5}$ & $\left(\sim 60 \times 10^{5}\right)$ \\
\hline
\end{tabular}

NoTE: Times are reported in seconds. In the composite ratios, first number is the weight percent of $\mathrm{SiO}_{2}$ in $\mathrm{SiO}_{2}-\mathrm{CH}_{3} \mathrm{SiO}_{3 / 2}$.

substituted silanes in $\mathrm{NH}_{3}$ catalysis drops rapidly. This decrease does not necessarily lead to longer gelation times because the gel formation could be caused by the tetraorthosilicate network only. As shown in reference 11 , the condensation rate increases with higher $\mathrm{pH}$ values, leading to shorter gelling times in the composite sol compared to the acid-catalyzed case. Because of the low hydrolysis rates in the basic case, the gelling occurs mainly from the $\mathrm{Si}(\mathrm{OR})_{4}$ hydrolysis and condensation, and the unhydrolyzed $\mathrm{CH}_{3}$-containing precursors can evaporate if the gels are dried shortly after gelling. IR spectra in the base-catalyzed case show a corresponding decrease of the $\mathrm{CH}_{3}$ signal in basic gels, too. If the composites are stored in a closed system for several weeks without drying after gelation to allow further reaction, higher yields can be obtained from basic catalysis, too. This process was carried out for surface area and $\mathrm{H}_{2} \mathrm{O}$ adsorption measurements.

To support the hypothesis of weaker pore wall interaction in the $\mathrm{CH}_{3}$ modified case, $\mathrm{H}_{2} \mathrm{O}$ adsorption experiments were carried out on several

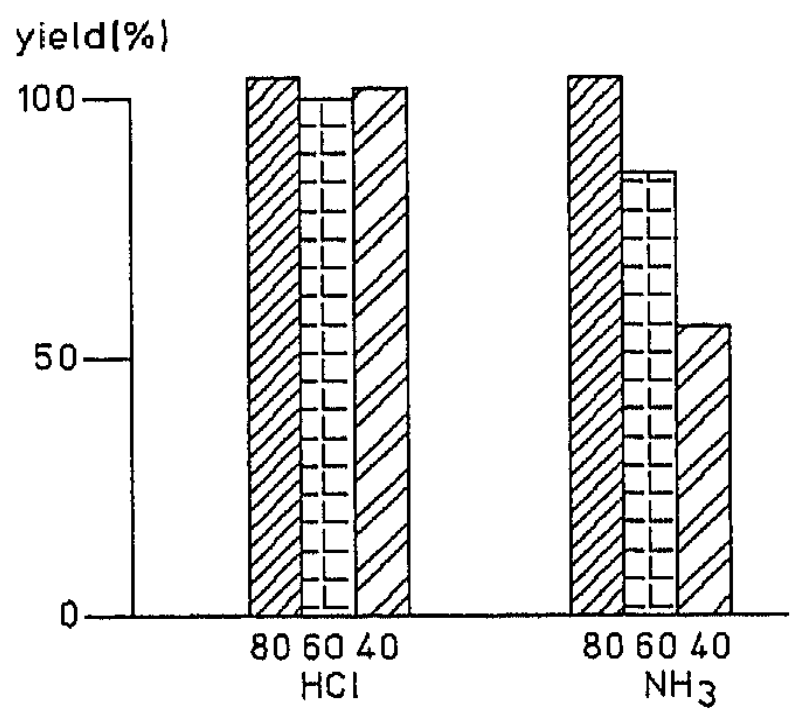

Figure 3. Percentage of product yield depending on catalyst and composition. The samples were dried after gelling to a constant weight at $110^{\circ} \mathrm{C}$; yields above $100 \%$ are due to residual water. Catalyst concentrations were $1.0 \mathrm{~N} \mathrm{NH}_{3}$ and $1 \mathrm{~N} \mathrm{HCl}$; abscissa numbers denote wt \% $\mathrm{SiO}_{2}$ in $\mathrm{SiO}_{2}-\mathrm{CH}_{3} \mathrm{SiO}_{3 / 2}$ composites. 


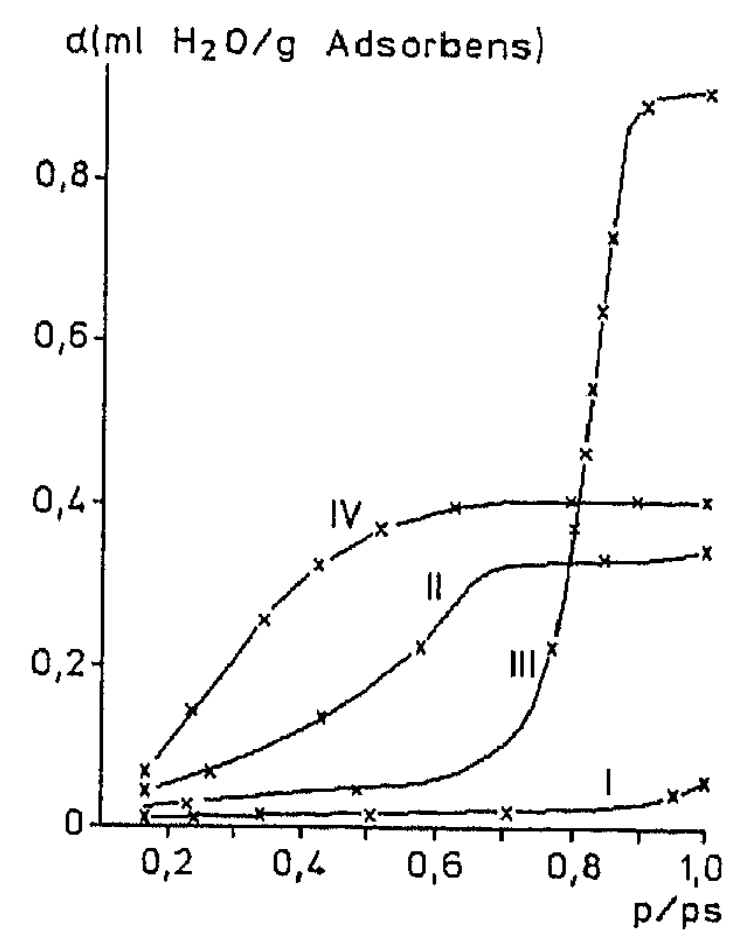

Figure 4. $\mathrm{H}_{2} \mathrm{O}$ adsorption isotherms (partial pressure over saturation pressure) on four different silicas: $\mathrm{I}, \mathrm{CH}_{3}-$ modified $300 \mathrm{~m}^{2} / \mathrm{g} ; \mathrm{II},-\mathrm{CH}_{2}-\mathrm{CH}_{2} \mathrm{COOH}-, 800$ $\mathrm{m}^{2} / \mathrm{g} ; \mathrm{III},\left(\mathrm{CH}_{2}\right)_{3} \mathrm{NH}_{2-}, 310 \mathrm{~m}^{2} / \mathrm{g}$; and IV, unmodified, $450 \mathrm{~m}^{2} / \mathrm{g}$.

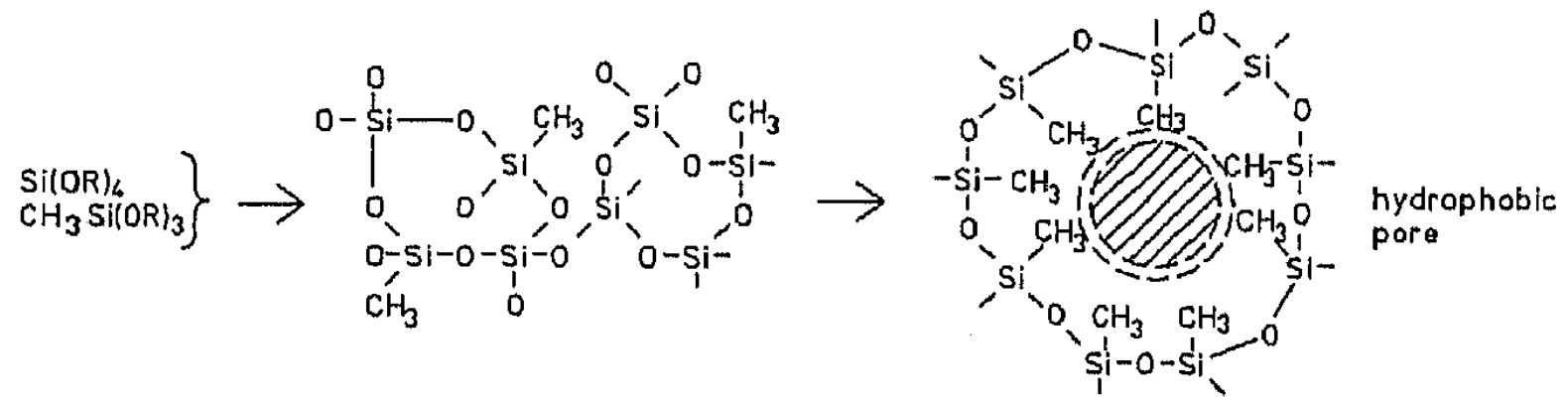

Scheme III. Self-arrangement of $\mathrm{CH}_{3}$-modified systems.

porous silica gels with different compositions (Figure 4). The $\mathrm{CH}_{3}$-modified system shows almost no $\mathrm{H}_{2} \mathrm{O}$ adsorption, a result indicating extremely hydrophobic pores. Increasing hydrophilicity (II $\rightarrow$ IV) changes the adsorption behavior gradually. During the condensation step of the $\mathrm{CH}_{3}$ containing gels, a self-adjustment of the system seems to take place, and the $\mathrm{CH}_{3}$ groups "turn" to the inner pore walls (Scheme III).

In summary, high-surface-area systems can be prepared from $\mathrm{CH}_{3}-\mathrm{Si} \equiv / \mathrm{SiO}_{2}$ and $\left(\mathrm{CH}_{3}\right)_{2} \mathrm{SI}=/ \mathrm{SiO}_{2}$ composites even if the network stiffness is expected to be decreased substantially, perhaps because of the decrease of interaction between hydrophobic (self-arranged) pore walls and $\mathrm{H}_{2} \mathrm{O}$ and the reduction of interfacial forces. 


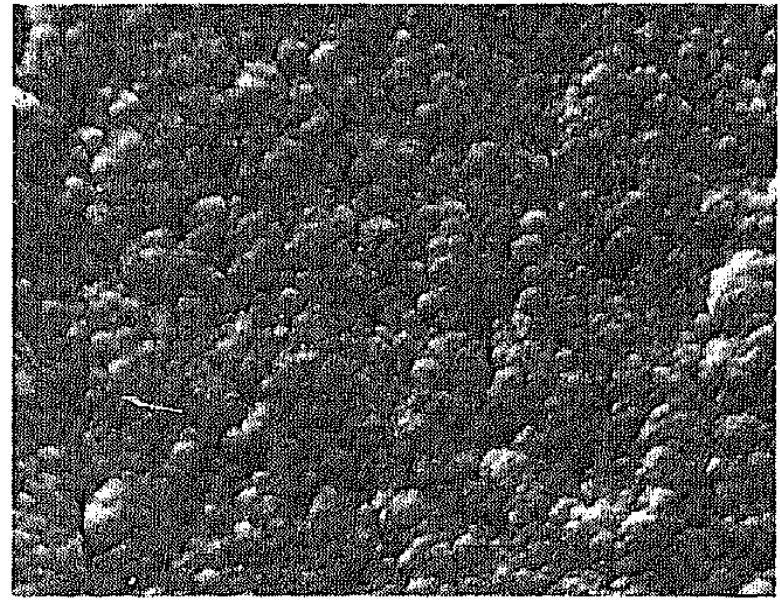

a

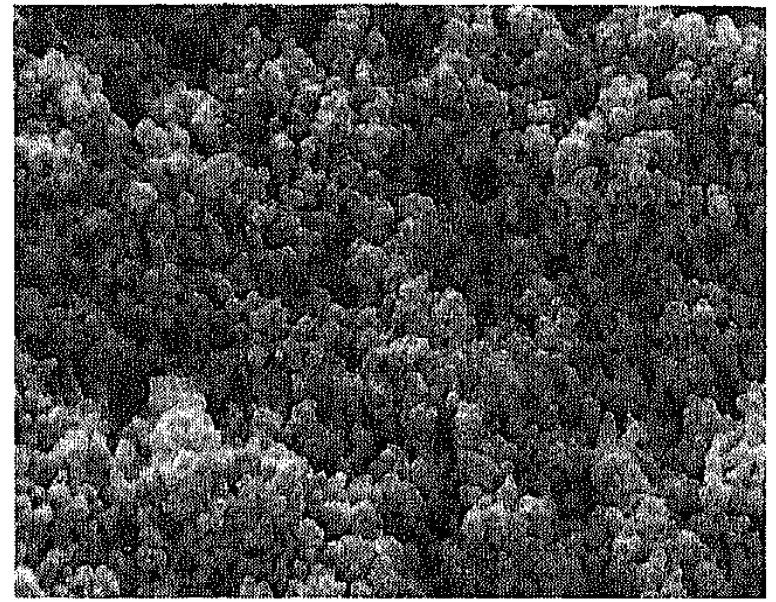

b

Figure 5. Images of gel surfaces: a, $0.1 \mathrm{~N} \mathrm{NH}_{3}, 450 \mathrm{~m}^{2} ; b, 6 \mathrm{~N} \mathrm{HCl}, 270 \mathrm{~m}^{2} \mathrm{~g}$. The bar is $4 \mu \mathrm{m}$.

The influence of the catalyst does not only affect the physical properties; the morphology can be influenced, too. Figure 5 shows two gels with $60 \mathrm{wt} \%\left(\mathrm{CH}_{3}\right)_{2} \mathrm{SiO}$ in a $\left(\mathrm{CH}_{3}\right)_{2} \mathrm{SiO} / \mathrm{SiO}_{2}$ composite. Whereas the $\mathrm{NH}_{3}$-catalyzed material is transparent, the $\mathrm{HCl}$-catalyzed material is cloudy. Pore analysis shows a maximum at radius $r$ of 4.2 and $500 \mathrm{~nm}$. The larger radii can be of interest as "transport pores" for kinetics in liquid adsorption processes. This example shows how processing conditions can be used for the generation of special microstructure properties.

Preparation of Materials with Special Functions. The porosity not only defines the adsorption parameters of a material, but also its mechanical stability. On the basis of this idea and the hydrolysis and condensation kinetics and its effect on microstructure, an abrasive powder was developed (12-13) with an abrasion-controlling mechanism for human skin. The investigation of the synthesis parameter shows a direct connection between the composition and the mechanical properties of the granular material (Figure 6). As expected from the previous experiments, $\mathrm{HCl}$ had to be used to provide reproducible $\mathrm{CH}_{3}$ concentrations and welldefined, reproducible material properties.

The increase of the abrasion number (not representing higher abrasion) at higher $\left(\mathrm{CH}_{3}\right)_{2} \mathrm{SiO}$ contents is misleading and due to the increasing elasticity of the grains, which is not covered by the test. For the hydrolysis and condensation step, $\mathrm{HCl}$ had to be used because $\mathrm{NH}_{3}$ did not lead to satisfying products for reasons pointed out in the section "Reactivity of Precursors in Sol-Gel Processes". The abrasive material was incorporated into a soap matrix and is used for the medical treatment of acne papulo pustulosa very successfully. It has been on the market for several years as a commercial product (14). 


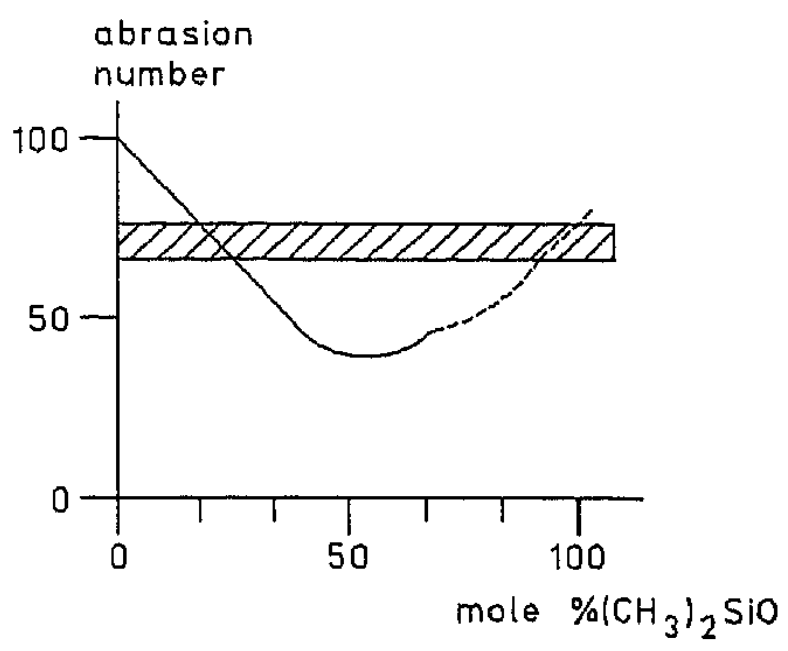

Figure 6. Abrasion numbers of a $\left(\mathrm{CH}_{3}\right)_{2} \mathrm{SiO}-\mathrm{SiO}_{2}$ composite. The number represents the fraction of unaffected grains of an average diameter of $0.3 \mathrm{~mm}$ (in percentage) after a special abrasion test (15). The hatched area represents abrasive behavior recognized to be satisfying by test persons. The dashed line represents data that were not useful because of elasticity.

To customize the adsorption of functional molecules, the incorporation of organic groupings increasing the interaction between the adsorbent and the molecule to be adsorbed should be an adequate method. Several mechanisms can be taken into consideration, for example, an acid-base or a hydrophobic interaction mechanism. If larger molecules such as enzymes are considered, the pore size plays an important role, and the area of the accessible surface is an important parameter, too. To create basic sites, various types of silica with amino groups were synthesized by cohydrolyzing $\left(\mathrm{CH}_{3} \mathrm{O}\right)_{3} \mathrm{Si}\left(\mathrm{CH}_{2}\right)_{3} \mathrm{NH}_{2}, \mathrm{Si}\left(\mathrm{OC}_{2} \mathrm{H}_{5}\right)_{4}$, and optionally $\left(\mathrm{CH}_{3}\right)_{2} \mathrm{Si}\left(\mathrm{OC}_{2} \mathrm{H}_{5}\right)_{2}$ at room temperature with $50 \mathrm{vol} \%$ methanol as solvent.

Because amino groups act autocatalytically (15-17) in the presence of water, for acid catalysis an excess of $\mathrm{HCl}$ was used to overcompensate the formation of $-\mathrm{NH}_{3}{ }^{+} \mathrm{Cl}^{-}$. In these cases, the gels were washed with methanol and water until no $\mathrm{Cl}^{-}$could be detected in the filtrate. How far the incorporation of amino groups into silica could affect the adsorption of acid components was of interest. Lactic acid and a sulfonic acid (a commercially available dye named Telon Light Yellow) were chosen as test components (18). In Figure 7 the adsorption isotherm of lactic acid is shown. Unmodified $\mathrm{SiO}_{2}$ does not have remarkable adsorption in aqueous solution under these circumstances. The result shows the effect of the amino modification quite clearly, because the lactic acid load of the adsorbent is remarkable, and it is difficult to adsorb small water-soluble molecules in an aqueous environment.

The kinetics of the adsorption are shown in Figure 8, which demonstrates an almost ideal breakthrough curve that indicates fast kinetics. The 


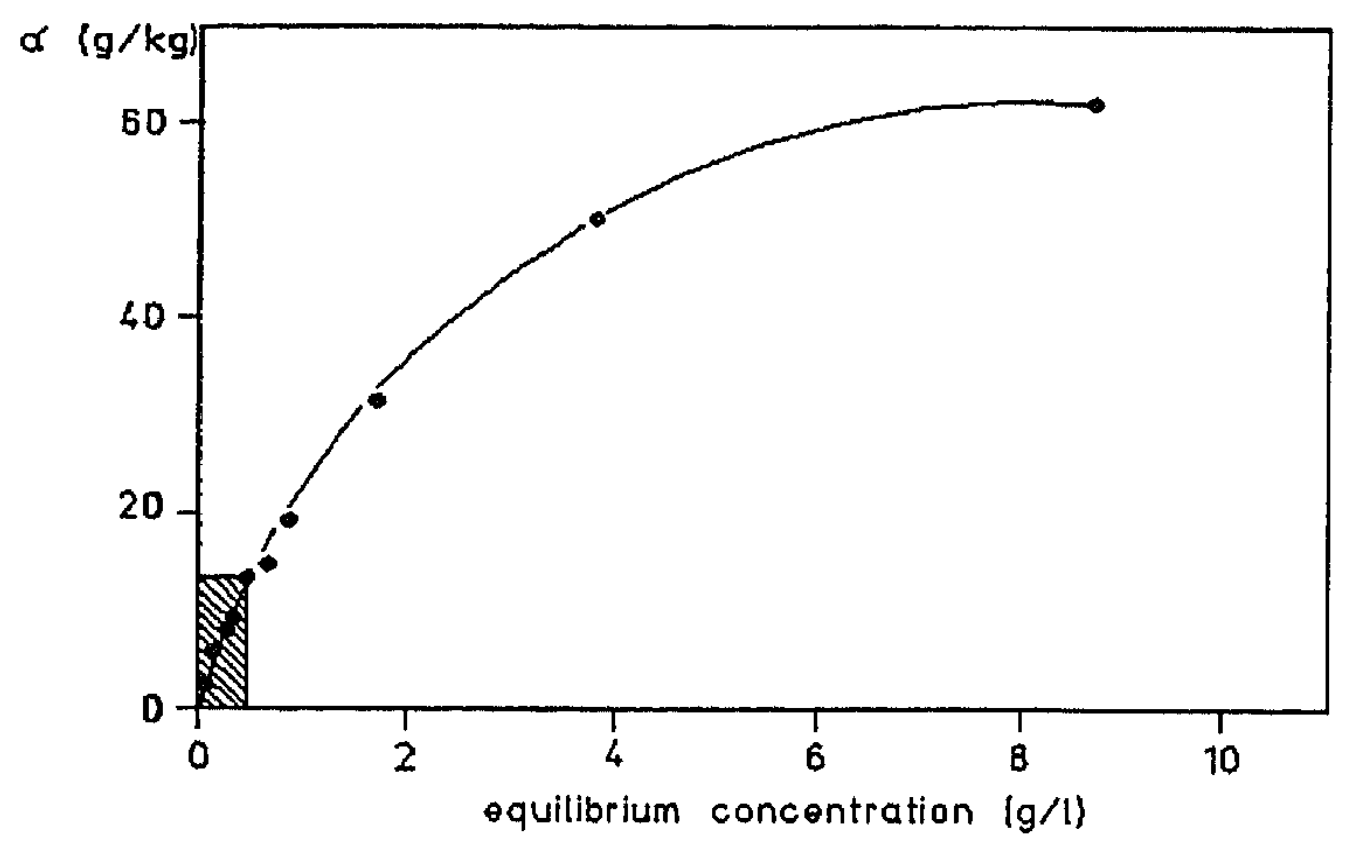

Figure 7. Adsorption isotherm of lactic acid on an amino-modified adsorbent. The composition was 5/95 (weight percent) in $\mathrm{NH}_{2}\left(\mathrm{CH}_{2}\right)_{3} \mathrm{SiO}_{3 / 2} / \mathrm{SiO}_{2}$. The mole surface was found to be $9.8 \times 10^{-5}-\mathrm{NH}_{2} / \mathrm{g}$; the method was that of reference 17. The BET surface area was $350 \mathrm{~m}^{2} / \mathrm{g}$; the hatched area indicates high loads even at low equilibrium concentrations.

breakthrough level represents almost the equilibrium value and does not depend on the flow rates used in the experiment. A glass tube $0.5 \mathrm{~cm}$ in diameter was used. Chemical analysis was carried out in steps of $5 \mathrm{~mL}$ to monitor the lactic acid concentration during the absorption experiment.

The sulfonic acid did not have remarkable adsorption under these circumstances. If, in addition to amino groups, a $\left(\mathrm{CH}_{3}\right)_{2} \mathrm{Si}=$ unit is incorporated, the adsorption rates increase remarkably. The best results were obtained with the composition $\mathrm{SiO}_{2}:\left(\mathrm{CH}_{3}\right)_{2} \mathrm{SiO}:$ amino $=40: 60: 2.5$ with $9 \mathrm{~N} \mathrm{HCl}$ as catalyst. The high concentration was found to lead to a maximum of load in a series of experiments with varying catalyst concentrations. The aromatic sulfonic acid could be loaded to $120 \mathrm{~g}$ per kilogram of adsorbent with an equilibrium concentration of $1.6 \mathrm{~g} / \mathrm{L}$ and to $26 \mathrm{~g} / \mathrm{kg}$ with $0.2 \mathrm{~g} / \mathrm{L}$ (Figure 9). This fact can be attributed to a "double function" adsorption mechanism of a hydrophobic interaction of $-\mathrm{CH}_{3}$ groups with the phenyl group of the sulfonic acid and the acid-based interaction. The kinetics of the flow experiments could be improved by microstructure tailoring (Figure 9 ) by variation of the catalyst concentration. Figure $9 \mathrm{~b}$ shows the optimized microstructure with "transport pores" and a surface area about three times that of the adsorbent in Figure 9 a.

Another interesting case is the adsorption of $\mathrm{CO}_{2}$, which does not show dipole moment but is able to dissociate with water to an ionic compound 


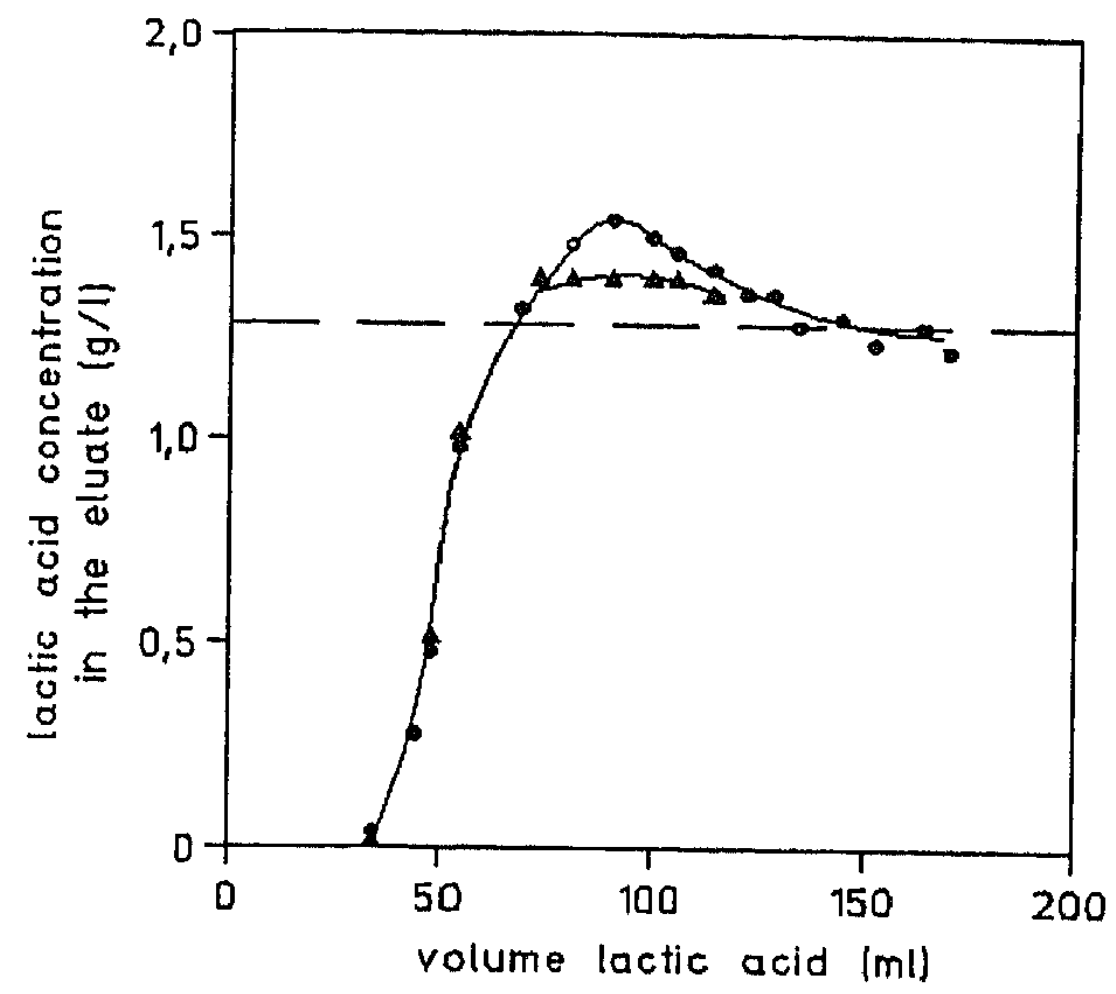

Figure 8. Breakthrough curves of a column-flow experiment. Flow rates were 2.0 (4) and $0.83(\bullet) \mathrm{mL} / \mathrm{min} ; 3 \mathrm{~g}$ of adsorbent was used. The dashed line indicates input lactic acid concentration.

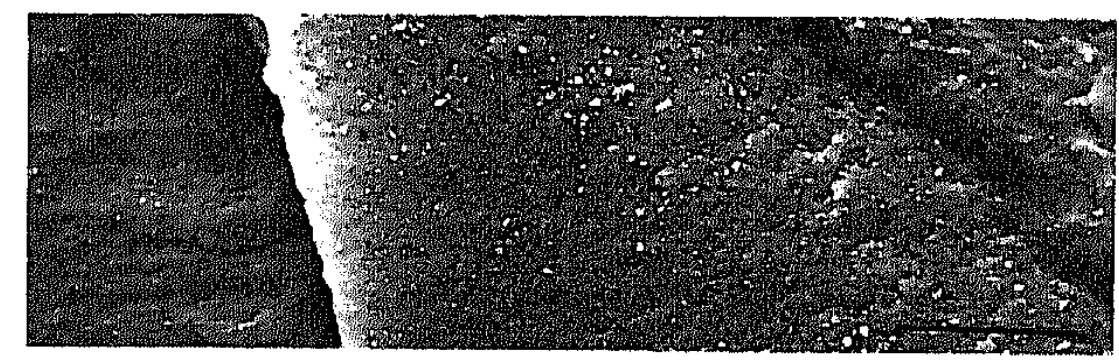

a

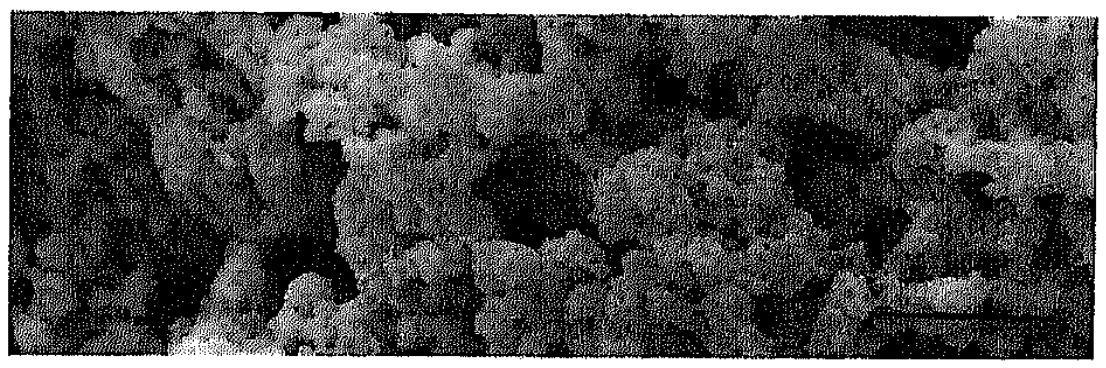

b

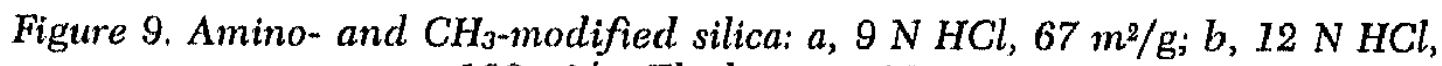
$188 \mathrm{~m}^{2} / \mathrm{g}$. The bars are $20 \mu \mathrm{m}$. 
according to $\mathrm{CO}_{2}+\mathrm{H}_{2} \mathrm{O} \rightleftharpoons \mathrm{H}_{2} \mathrm{CO}_{3} \rightleftharpoons \mathrm{H}^{+}+\mathrm{HCO}_{3}^{-}$. The question arises whether amino groups in combination with water adsorbed to the pore walls are able to act in a dissociative way for the adsorption of $\mathrm{CO}_{2}$ according to $\mathrm{H}^{+} \mathrm{CO}_{3}^{-}+\mathrm{H}_{2} \mathrm{~N}-\rightarrow \mathrm{HCO}_{3}^{-}+\mathrm{H}_{3} \mathrm{~N}^{+}$. Therefore, a series of adsorbents with varying $-\mathrm{NH}_{2}$ concentrations were prepared, and the adsorption isotherms were determined. The influence of $\mathrm{H}_{2} \mathrm{O}$ on the adsorption isotherms was determined by thermogravimetric analysis (TGA) with a $\mathrm{N}_{2}$ gas flow loaded with water vapor. The adsorbents loaded with $\mathrm{CO}_{2}$ were flushed with the $\mathrm{H}_{2} \mathrm{O}$-containing $\mathrm{N}_{2}$, and the $\mathrm{H}_{2} \mathrm{O}$ content of the gels was determined after the experiment. The evaluation of the mass balance and the amount of residual water led to the conclusion that the $\mathrm{H}_{2} \mathrm{O}$ completely replaces the adsorbed $\mathrm{CO}_{2}$. On the other hand, as a function of the $\mathrm{NH}_{2}$ content, remarkable amounts of $\mathrm{CO}_{2}$ were able to be adsorbed on adsorbents dried at $150{ }^{\circ} \mathrm{C}$. These adsorbents show far lower $\mathrm{OH}$ peaks in the IR spectra than pure silica. This observation indicates that the ionic mechanism does not play any role, and a weak dipole interaction is postulated instead:

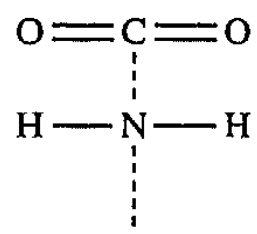

IR spectra, however, did not show a significant shift of the $=\mathrm{C}=\mathrm{O}$ vibration. Figure 10 shows some of the most important results.

The $\mathrm{NH}_{2}$ groups affect the amount of adsorbed $\mathrm{CO}_{2}$ as well as the thermal behavior and illustrate the change of thermodynamics with composition. At higher pressures (not displayed in Figure 10), the aminomodified adsorbents show a saturation plateau around 5 bar $\mathrm{CO}_{2}$ and a load of about 5-10 wt \% $\mathrm{CO}_{2}$, depending weakly on the surface area, whereas the $\mathrm{CH}_{3}$-modified material $\left(880 \mathrm{~m}^{2} / \mathrm{g}\right)$ shows no significant plateau up to 15 bars (the end of the test) and a load of about 36 wt \% at room temperature, which is an extremely high load. This observation leads to the question of whether these materials can be used for $\mathrm{CO}_{2}$ storage or as propellants with $\mathrm{CO}_{2}$. In reference 19, a heat pump is proposed; it uses two types of tailored adsorbents for $\mathrm{CO}_{2}$ in a closed-system process.

The determination of the heat of adsorption shows higher values on adsorbents with amino contents above $10 \mathrm{~mol} \%$ (e.g., $\mathrm{SiO}_{2}, 45 \mathrm{~kJ} / \mathrm{mol} ; 10$ $-\mathrm{NH}_{2}, 43 \mathrm{~kJ} ; 20-\mathrm{NH}_{2}, 58 \mathrm{~kJ} ; 30-\mathrm{NH}_{2}, 65 \mathrm{~kJ}$; experimental error, $\pm 7 \%$ ) and a decay as a function of the $\mathrm{CO}_{2}$ surface coverage (e.g., in an adsorbent with $20 \mathrm{~mol} \%-\mathrm{NH}_{2}$ from $58 \mathrm{~kJ} / \mathrm{mol} \equiv 2 \mathrm{~mL} \mathrm{CO} 2$ per gram to $17 \mathrm{~kJ} / \mathrm{mol}$ $\equiv 10 \mathrm{~mL} \mathrm{CO} \mathrm{CO}_{2}$ per gram). Thus, the amino-modified materials interact rather strongly in the first step with the $\mathrm{CO}_{2}$, and the interaction decreases 


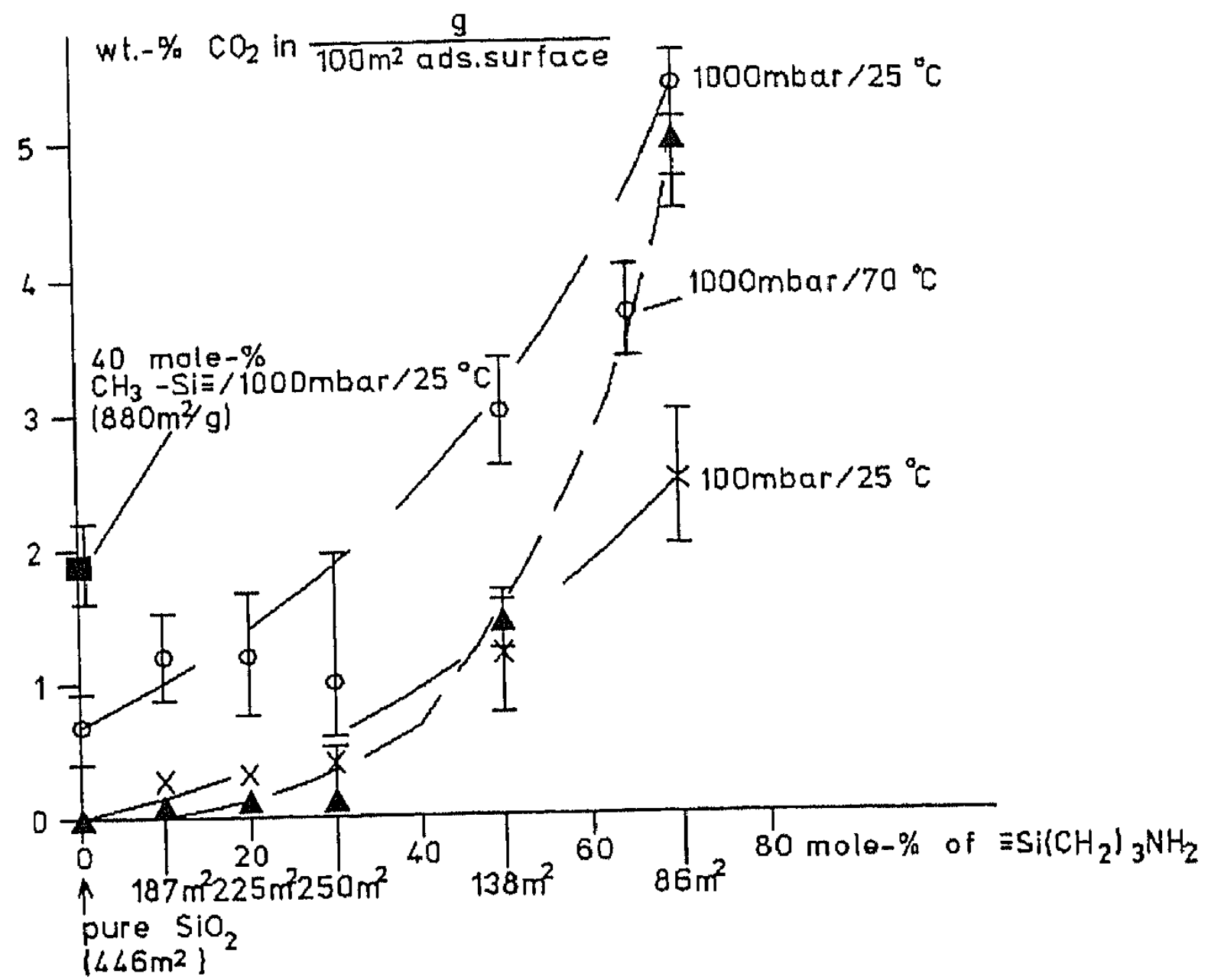

Figure 10. $\mathrm{NH}_{2}$-containing silica with $\mathrm{CO}_{2}$ at 100 and $1000 \mathrm{mbar}$ and two different temperatures. The load is normalized on $100-\mathrm{m}^{2} / \mathrm{g}$ surface area. Data of pure silica and a-CH3-modified silica are given for comparison; the numbers with $\mathrm{m}^{2}$ as units at the abscissa display the surface areas of the investigated adsorbents.

with increasing load; this observation suggests a population of various adsorption sites.

\section{Conclusions}

The organic bulk modification of silica can be used for tailoring specific surface properties. One advantage of this reaction route is the possibility to use a one-step process, but the reaction must be controlled very carefully. Multifunctional materials can be synthesized, too.

\section{Acknowledgments}

We thank the Bundesminister für Forschung und Technologie of the Federal Republic of Germany and Ruhrgas Company for financial support. We also thank J. Strutz for experimental work and helpful discussions. 


\section{References}

1. Iler, R. K. The Chemistry of Silica; Wiley: New York, 1979; pp 462-714.

2. Hench, L. L.; West, J. K.; Zhu, B. F. In SPIE Proceedings of Sol-Gel Optics; SPIE: San Diego, CA, 1990; Vol. 1328, pp 230-240.

3. Sakka, S. In Sol-Gel Technology for Thin Films, Fibers, Preforms, Electronics and Speciality Shapes; Klein, L. C., Ed.; Noyes Publications: Park Ridge, NJ, 1988; p 140.

4. Achtsnit, H.-D.; Wegerhoff, W. Oral presentation at German Glass Forum Meeting, May 1990.

5. Scherer, G. W.; Brinker, C. J. The Physics and Chemistry of Sol-Gel Processing; Academic Press: New York, 1990; pp 204-209.

6. Aerosil (Technical Bulletin); Degussa: Hanau, Germany, 1970.

7. Lab-O-Sil, CGEN-7, Cabot Corporation: Boston, 1970.

8. Bagley, B. G.; Quinn, W. E.; Khan, S. A.; Barboux, P.; Tarascon, J.-M. J. NonCryst. Solids 1990, 121, 454.

9. Schmidt, H.; Scholze, H.; Kaiser, A. J. Non-Cryst. Solids 1984, 63, 1.

10. Kaiser, A.; Schmidt, H. J. Membr. Sci. 1985, 22, 257.

11. Schmidt, H.; Kaiser, A.; Rudolph, M.; Lentz, A. In Science of Ceramic Chemical Processing; Hench, L. L.; Ulrich, D. R., Eds.; Wiley: New York, 1986; p 87.

12. Coltrain, B. K.; Melpolder, S. M.; Salva, J. M. In Proc. IVth Intl. Conf. on Ultrastructure of Ceramics, Glasses and Composites; Uhlmann, D. R.; Ulrich, D. R., Eds.; Wiley: New York, 1989; pp 69-76.

13. Schmidt, H.; Kaiser, A.; Patzelt, H.; Scholze, H. J. Phys. 1982, 43 (C9, suppl. 12), 275.

14. Kompa, H. E.; Franz, H.; Wiedey, K. D.; Schmidt, H.; Kaiser, A.; Patzelt, H. Ärztliche Kosmetologie 1983, 13, 193.

15. Jaikin Neu; Basotherm Company: Biberach-Riss, Germany, 1985.

16. Ravaine, D.; Seminel, A.; Charbouillot, Y.; Vincens, M. J. Non-Cryst. Solids 1986, 82, 210 .

17. Schmidt, H.; Popall, M.; Rousseau, F.; Poinsignon, C.; Armand, M. In Proc. 2nd Intl. Symp. on Polymer Electrolytes; Stosati, B., Ed.; Elsevier: London; $\mathrm{p}$ 325.

18. Schmitt, H. W.; Walker, J. E. FEBS Lett. 1977, 81, 403.

19. Schmidt, H.; Strutz, J.; Gerritsen, H.-G.; Mühlmann, H. German patent 3518 $738,1986$.

RECEIVED for review October 19, 1990. ACCEPTED revised manuscript April 20, 1992. 